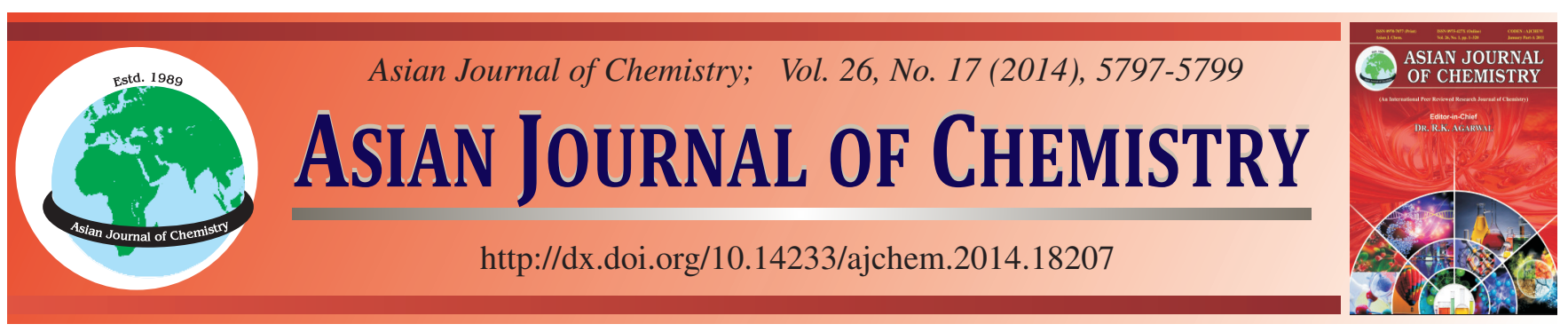

\title{
Synthesis and Characterization of Non-Toxic Thermal Stabilizers of PVC Based on Layered Double Hydroxides $\dagger$
}

\author{
Eunju Park ${ }^{1}$, Jinae LeE $^{2}$ and Hyung WoOK Park ${ }^{1, *}$
}

${ }^{1}$ School of Mechanical and Nuclear Engineering, Ulsan National Institute of Science and Technology, 100 Banyeon-ri, Eonyang-eup, Ulju-gun, Ulsan Metropolitan City, 689-798, Republic of Korea

${ }^{2}$ Department of Statistics, University of Georgia, Athens, Georgia, 30602, USA

*Corresponding author: Fax:+82 52 2172409; Tel: +82 52 2172319; E-mail : hwpark@unist.ac.kr

Hydrotalcite-like compounds are expressed by the general formula $\left[\mathrm{M}\left({ }^{2+}\right)_{1 \times} \mathrm{M}\left({ }^{3+}\right)_{\mathrm{x}}(\mathrm{OH})_{2}\right]^{\mathrm{x}+1} \mathrm{~A}^{\mathrm{n}-}{ }_{\mathrm{x} / \mathrm{n}} \cdot \mathrm{mH}_{2} \mathrm{O}$, where $\mathrm{M}\left({ }^{2+}\right)$ and $\mathrm{M}\left({ }^{3+}\right)$ are divalent and trivalent cations, respectively. $\mathrm{Mg}_{1-\mathrm{x}} \mathrm{Al}_{\mathrm{x}}(\mathrm{OH})_{2} \mathrm{CO}^{\mathrm{n}-}{ }_{\mathrm{x} / \mathrm{n}} \cdot \mathrm{mH}_{2} \mathrm{O}$ structures, non-toxic thermal stabilizers of poly(vinyl chloride), were manufactured by various coprecipitation methods to optimize the manufacturing process of non-toxic thermal stabilizers of poly(vinyl chloride). These hydrotalcite-like compounds were characterized by field-emission-scanning electron microscopy, X-ray diffraction, thermal analysis and transmittance spectra. Samples were fabricated using different steps and a base reactant produced the most stable sample. The cell parameter c is related to the thickness of the brucite-like layer and the interlayer distance was $23.21 \AA$.

Keywords: Hydrotalcite-like compound, Thermal stabilizers, Poly(vinyl chloride), Brucite-like layer, Co-precipitation.

\section{INTRODUCTION}

Recently, layered double hydroxides (LDH) have received a great deal of attention because of their potential applications. Layered double hydroxidess, also known as anionic clays or hydrotalcite-like compounds (HTlc), are naturally rare and are relatively simple and inexpensive to synthesize on the laboratory scale. Layered double hydroxides have been used as polymer stabilizers, anion exchangers, adsorbents, catalysts and anion scavengers ${ }^{1-3}$.

Polyvinyl chloride (PVC) is an important thermoplastic resin with different applications ${ }^{2}$. However, PVC is highly unstable upon exposure to heat or ultraviolet (UV) light; thus, researchers are investigating techniques to improve its thermal stability. Layered double hydroxides are well suited as nontoxic stabilizers, because they consist of magnesium, aluminum and zinc and thus, they are non-toxic. Layered double hydroxides have a high absorption capacity for $\mathrm{HCl}$ and are used as thermal stabilizers of PVC.

Hydrotalcite-like compounds consists of positively charged layers with anionic interlayers. The general formula of hydrotalcite-like compounds is $\left[\mathrm{M}\left({ }^{2+}\right)_{1-\mathrm{x}} \mathrm{M}\left({ }^{3+}\right)_{\mathrm{x}}(\mathrm{OH})_{2}\right]^{\mathrm{x}+1} \mathrm{~A}^{\mathrm{n}-}{ }_{\mathrm{x} / \mathrm{n}} \cdot \mathrm{mH}_{2} \mathrm{O}$, where $\mathrm{M}\left({ }^{2+}\right)$ is a divalent cation $\left.\left(\mathrm{Mg}^{2+}, \mathrm{Ni}^{2+}, \mathrm{Zn}^{2+}, \mathrm{Co}^{2+}\right), \mathrm{M}^{3+}\right)$ is a trivalent cation $\left(\mathrm{Al}^{3+}, \mathrm{Fe}^{3+}, \mathrm{Ga}^{3+}, \mathrm{Cr}^{3+}\right)$ and $\mathrm{A}$ is an anion with charge $\mathrm{n}\left(\mathrm{HO}^{-}, \mathrm{CO}_{3}{ }^{2}, \mathrm{NO}^{3-}, \mathrm{Cl}^{-}, \mathrm{SO}_{4}{ }^{2-}\right)$. That is, hydrotalcite- like compounds consist of a positively charged brucite-like layer $\left[\mathrm{Mg}_{1-\mathrm{x}} \mathrm{Al}_{\mathrm{x}}(\mathrm{OH})_{2}\right]^{\mathrm{x}+1}$ and negatively charged interlayers $\left[\mathrm{A}_{\mathrm{x} / \mathrm{n}}{ }^{\mathrm{n}-} \cdot \mathrm{mH}_{2} \mathrm{O}\right]^{\mathrm{x}-}$. Magnesium and aluminium are randomly distributed among the octahedral positions ${ }^{4}$.

Hydrotalcite-like compounds can be synthesized by various techniques, such as hydrothermal treatment and synthesis ${ }^{5,6}$, coprecipitation, urea hydrolysis ${ }^{7}$, sol-gel methods ${ }^{8}$ and microwave irradiation $^{9,10}$. Coprecipitation is the most commonly technique used to synthesize hydrotalcite-like compounds. This method provides flexibility in the layer charge density. Additionally, a wide variety of anionic species can be directly intercalated between the hydroxylated sheets.

In this study, we synthesized hydrotalcite powder as a nontoxic stabilizer of PVC using various coprecipitation combinations. The different characteristics are discussed based on four different process steps. The thermal stability of hydrotalcite-like compounds is important because the manufacturing temperature during a production of plastics, such as PVC, may reach $200^{\circ} \mathrm{C}$. In these experiments, various process combinations were used to improve the thermal stability of hydrotalcite-like compounds. To confirm the thermal behaviour of hydrotalcite-like compounds, we measured the thermogravimetry of different samples using a differential thermal analyzer. The microstructures were characterized by X-ray diffraction. Chemical bonds were analyzed using Fourier-transform infrared spectroscopy. 
EXPERIMENTAL

Hydrotalcite-like compounds were prepared by four different coprecipitation methods. Important factors that were considered include the nature of the anions, $\mathrm{pH}$, temperature, aging and synthesis technique. Among these factors, $\mathrm{pH}$ control during precipitation led to different properties of the hydrotalcite-like compounds. In this study, all samples were synthesized using the same molar ratios. However, the process was conducted in several steps.

Sample 1: An acid reactant was prepared from a mixture of $\mathrm{Mg}\left(\mathrm{NO}_{3}\right)_{2} \cdot 6 \mathrm{H}_{2} \mathrm{O}(0.38 \mathrm{~mol})$ and $\mathrm{Al}\left(\mathrm{NO}_{3}\right)_{3} \cdot 9 \mathrm{H}_{2} \mathrm{O}(0.127 \mathrm{~mol})$ in deionized water. A base reactant was prepared from a mixture of $\mathrm{NaOH}(1.2 \mathrm{~mol})$ and $\mathrm{Na}_{2} \mathrm{CO}_{3}(0.2 \mathrm{~mol})$ in deionized water. The two reactants were added to deionized water in a Pyrex reactor until the $\mathrm{pH}$ reached 10 . After the reaction, the suspension was kept for $24 \mathrm{~h}$ at $90^{\circ} \mathrm{C}$ with stirring. The hydrotalcite powder was collected by filtration and washed several times with deionized water until the $\mathrm{pH}$ was neutral. The powder was dried at $60{ }^{\circ} \mathrm{C}$ overnight.

Sample 2: An acid reactant was prepared from a mixture of $\mathrm{Mg}\left(\mathrm{NO}_{3}\right)_{2} \cdot 6 \mathrm{H}_{2} \mathrm{O}(0.38 \mathrm{~mol})$ and $\mathrm{Al}\left(\mathrm{NO}_{3}\right)_{3} \cdot 9 \mathrm{H}_{2} \mathrm{O}(0.127 \mathrm{~mol})$ in deionized water. A base reactant was prepared from a mixture of $\mathrm{NaOH}(0.9 \mathrm{~mol}), \mathrm{KOH}(90 \%, 0.3 \mathrm{~mol})$ and $\mathrm{Na}_{2} \mathrm{CO}_{3}$ $(0.2 \mathrm{~mol})$ in deionized water. The two reactants were added to deionized water in a Pyrex reactor until the $\mathrm{pH}$ reached 10. After the reaction, the suspension was kept for $24 \mathrm{~h}$ at $90{ }^{\circ} \mathrm{C}$ with stirring. The hydrotalcite powder was collected by filtration and washed several times with deionized water until the $\mathrm{pH}$ was neutral. The powder was dried at $60^{\circ} \mathrm{C}$ overnight.

Sample 3: In a Pyrex reactor, a base reactant was prepared from a mixture of $\mathrm{NaOH}(1.2 \mathrm{~mol})$ and $\mathrm{Na}_{2} \mathrm{CO}_{3}(0.2 \mathrm{~mol})$ in deionized water at $25-35^{\circ} \mathrm{C}$. The $\mathrm{pH}$ was maintained at 10 by adding a mixture of $\mathrm{Mg}\left(\mathrm{NO}_{3}\right)_{2} \cdot 6 \mathrm{H}_{2} \mathrm{O}(0.38 \mathrm{~mol}), \mathrm{Al}\left(\mathrm{NO}_{3}\right)_{3} \cdot 9 \mathrm{H}_{2} \mathrm{O}$ $(0.127 \mathrm{~mol})$ and deionized water. After the reaction, the suspension was kept for $24 \mathrm{~h}$ at $90^{\circ} \mathrm{C}$ with stirring. The hydrotalcite powder was collected by filtration and washed several times with deionized water until the $\mathrm{pH}$ was neutral. The powder was dried at $60{ }^{\circ} \mathrm{C}$ overnight.

Sample 4: In a Pyrex reactor, a base reactant was prepared from a mixture of $\mathrm{MgSO}_{4}(0.38 \mathrm{~mol})$ and $\mathrm{Al}_{2}\left(\mathrm{SO}_{4}\right)_{3}(0.127 \mathrm{~mol})$ in deionized water at $25-35^{\circ} \mathrm{C}$. The $\mathrm{pH}$ was maintained at 10 by adding a mixture of $\mathrm{NaOH}(1.2 \mathrm{~mol}), \mathrm{Na}_{2} \mathrm{CO}_{3}(0.2 \mathrm{~mol})$ and deionized water. After the reaction, the suspension was kept for $24 \mathrm{~h}$ at $90{ }^{\circ} \mathrm{C}$ with stirring. The hydrotalcite powder was collected by filtration and washed several times with deionized water until the $\mathrm{pH}$ was neutral. The powder was dried at $60^{\circ} \mathrm{C}$ overnight.

The morphologies of the powders were observed by fieldemission-scanning electron microscopy. The structures were analyzed by X-ray diffraction. The thermal decomposition of layered double hydroxides is important, giving rise to mixed oxides of industrial interest for catalytic or other practical applications. Thermal analysis using thermogravimetric-differential thermal analysis techniques was used to determine massloss steps, measure the temperature of mass-loss steps and identify the mechanism of mass loss. Fourier-transform infrared spectroscopy measurements were performed in the absorption/ transmission mode to investigate chemical bonding characteristics.

\section{RESULTS AND DISCUSSION}

The FE-SEM images (Fig. 1) show the morphologies of the synthesized hydrotalcite powders. The particles in sample 1 were hexagonal platelets and samples 2, 3 and 4 were porouslike particles. Thus, the shape of hydrotalcite-like compounds was adjusted according to the process combination.
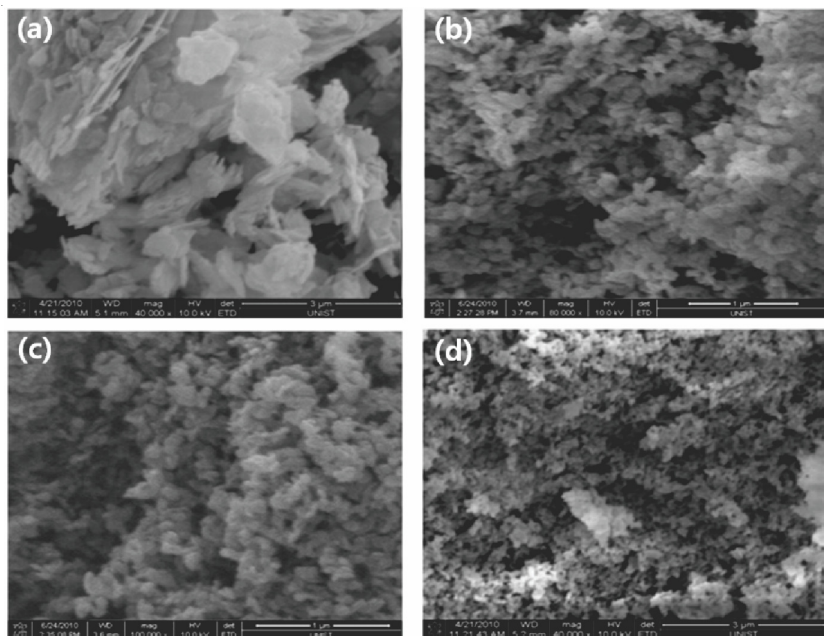

Fig. 1. SEM micrographs of (a) sample 1, (b) sample 2, (c) sample 3 and (d) simple 4

Fig. 2 shows the XRD patterns of coprecipitation-synthesized hydrotalcite powders. No other crystalline phases were detected in the XRD patterns. The cell parameters obtained from the (003) and (110) interplanar distances estimated from Fig. 2 are $\mathrm{a}=3.04 \AA, \mathrm{c}=22.98 \AA$ for sample $1, \mathrm{a}=3.063 \AA$, $\mathrm{c}=23.308 \AA$ for sample $2, \mathrm{a}=3.059 \AA, \mathrm{c}=23.210 \AA$ for sample 3 and $\mathrm{a}=3.06 \AA, \mathrm{c}=23.3 \AA$ for sample 4 . The parameter $\mathrm{a}$ is the cation-cation distance within the brucite-like layer. The parameter $\mathrm{c}$ is related to the thickness of the brucitelike layer and the interlayer distance.

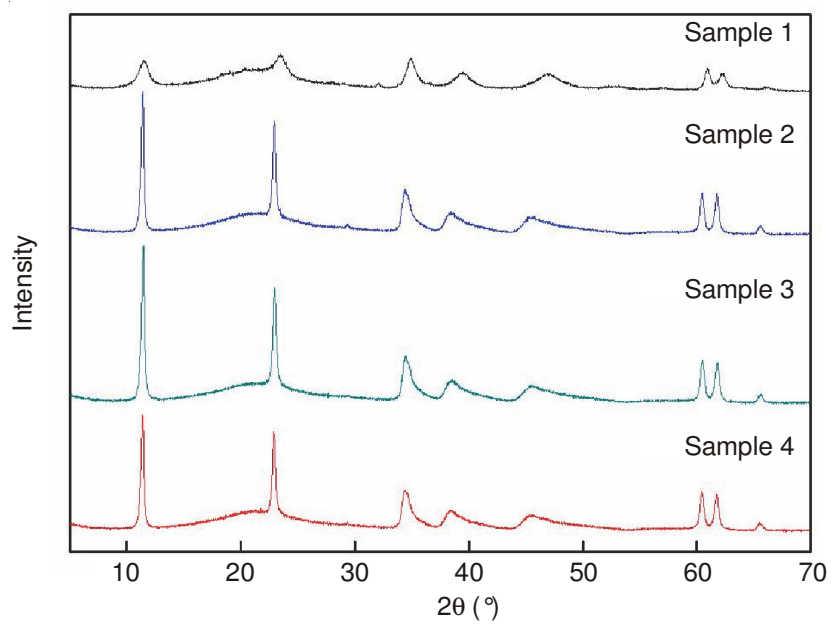

Fig. 2. XRD patterns of the samples

The c/ 3 value of sample 1 was $7.76 \AA$, consistent with the value of $7.69 \AA$ reported for the hydrotalcite-like compounds carbonate. This value confirms the crystalline structure of the samples and indicates a relatively well-ordered sheet arrangement, in agreement with that of a previous report ${ }^{10}$. 
Fig. 3 shows the FT-IR spectra of the four samples. $\mathrm{H}_{2} \mathrm{O}$ and $\mathrm{CO}_{3}{ }^{2-}$ between the layers correspond to the bands in the $4000-1200 \mathrm{~cm}^{-1}$ region and the M-O stretching bands were observed in the $1200-600 \mathrm{~cm}^{-1}$ region. The bands in the $1200-$ $600 \mathrm{~cm}^{-1}$ region were attributed to the lattice vibrations of oxygen ions in the interlayer, such as Mg-Al-O stretching and bending modes and $\mathrm{Mg}-\mathrm{O}$ and $\mathrm{Al}-\mathrm{O}$ stretching modes.

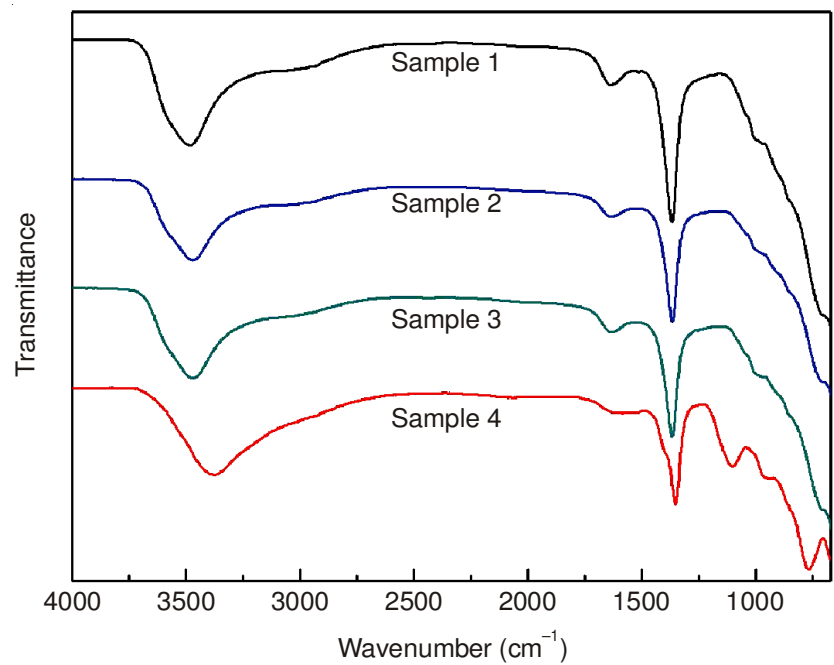

Fig. 3. FT-IR spectra for the samples

The broad band in the $3500-3300 \mathrm{~cm}^{-1}$ region was attributed to the $\mathrm{OH}$ stretching $(\mathrm{v}(\mathrm{OH}))$ mode of water molecules in the interlayer. For this broad peak, a shoulder at $3000 \mathrm{~cm}^{-1}$ was attributed to $v(\mathrm{OH})$, due to hydrogen bonding between water molecules and interlayer carbonate anions. The peak at $1635-1630 \mathrm{~cm}^{-1}$ shows the $\mathrm{OH}$ bending $\left(\delta\left(\mathrm{H}_{2} \mathrm{O}\right)\right)$ of water molecules. The $v_{3}$ symmetric-stretching mode of carbonate in the interlayer was observed in the $1480-1300 \mathrm{~cm}^{-1}$ region.

Fig. 4 shows the TG-DTA curves of coprecipitationsynthesized hydrotalcite powders and the weight loss of each stage. Except for sample 4, there were three stages of weight loss, but the second and third stages overlapped. In the temperature range of $80-200{ }^{\circ} \mathrm{C}$, the first stage, weight loss was due to dehydration of the interlayer. The second region (300-350 ${ }^{\circ} \mathrm{C}$ ), corresponds to weight loss due to dehydroxylation. This stage represents the process of decomposition of $\mathrm{OH}$ groups in the brucite layer. The range of $350-400{ }^{\circ} \mathrm{C}$, the third stage, corresponds to weight loss due to de-carbonation reactions.

\section{Conclusion}

This study synthesized hydrotalcite-like compounds as non-toxic thermal stabilizers of PVC using various coprecipitation methods. No unexpected phases were detected for the four different hydrotalcite-like compounds powders. XRD results provided a and c values. FT-IR spectra were similar for all samples, except sample 4, which showed unique bands in the $1200-600 \mathrm{~cm}^{-1}$ region. Thermal stability is an important
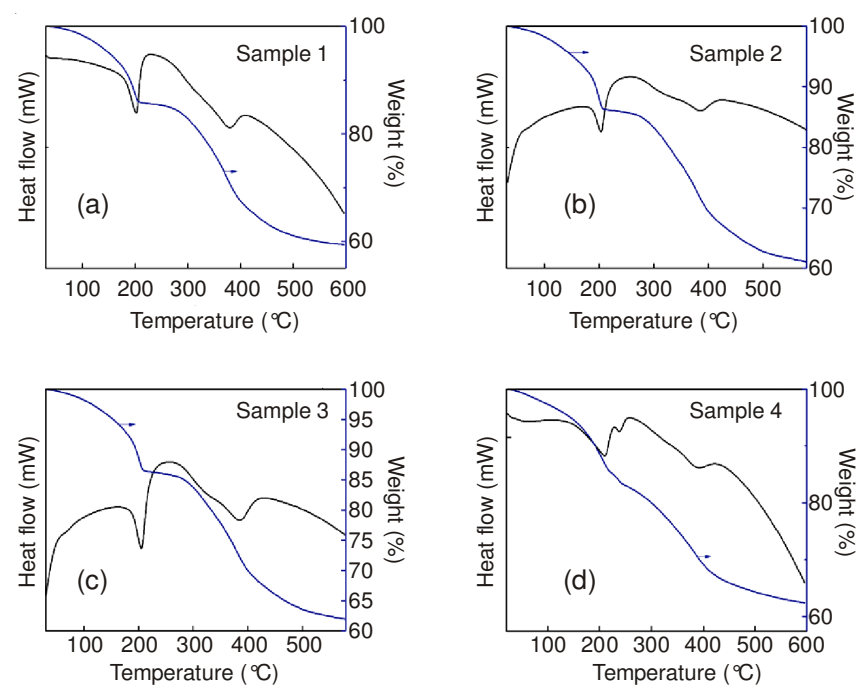

Fig. 4. TG-DTA curves of (a) sample 1, (b) sample 2, (c) sample 3 and (d) simple 4

property for thermal stabilizers of plastics such as PVC. TG-DTA results showed that the coprecipitation-synthesized hydrotalcite-like compounds powders were stable at $400{ }^{\circ} \mathrm{C}$. This work introduced a synthetic method for stable hydrotalcite-like compounds powders by coprecipitation. These results may help in predicting possible stabilizers for hightemperature applications.

\section{ACKNOWLEDGEMENTS}

This work was supported by the Human Resource Training Project for Regional Innovation funded by Ministry of Education, Science Technology (MEST) and National Research Foundation (NRF) of Korea (No. 2012H1B8A2026133) and Development of Nano-based Ultraprecision Hybrid Machining System Technology by the Ministry of Knowledge Economy (MKE) of Korea.

\section{REFERENCES}

1. Y. Kuang, L. Zhao, S. Zhang, F. Zhang, M. Dong and S. Xu, Materials, 3, 5220 (2010).

2. $\quad$ K.-H. Goh, T.-T. Lim and Z. Dong, Water Res., 42, 1343 (2008).

3. T. Kameda, T. Yoshioka, F. Yabuuchi, M. Uchida and A. Okuwaki, J. Mater. Sci., 42, 2194 (2007).

4. R. Allmann and B. Section, Struct. Crystallogr. Crystal Chem., 24, 972 (1968).

5. E.J. Park, S.D. Park, I.C. Bang, Y.-B. Park and H.W. Park, Mater. Lett., 81, 193 (2012).

6. H. Wang, H. Yi, P. Ning, X. Tang, L. Yu, D. He and S. Zhao, Chem. Eng. J., 166, 99 (2011).

7. H.-Y. Zeng, X. Deng, Y.-J. Wang and K.-B. Liao, AIChE J., 55, 1229 (2009).

8. J. Chandradass and M. Balasubramanian, Mater. Manuf. Process., 23, 158 (2008).

9. P. Benito, I. Guinea, F.M. Labajos and V. Rives, J. Solid State Chem., 181, 987 (2008).

10. G. Fetter, F. Hernández, A.M. Maubert, V.H. Lara and P. Bosch, J. Porous Mater, 4, 27 (1997). 